\title{
Methods and solutions for galvanic waste water treatment
}

\author{
Nikolay Makisha, ${ }^{1, *}$, Maria Yunchina ${ }^{1}$ \\ ${ }^{1}$ Moscow state University of civil engineering, Yaroslavskoyeshosse, 26, Moscow, 129337, Russia
}

\begin{abstract}
Currently galvanic sludge is considered as one of the most dangerous wastes, which are formed during purification of galvanic wastewater. The slimes of galvanic production are the most toxic industrial waste and sources of heavy metals emitted into the environment. Galvanic sludge belongs to the third hazard class; these wastes need to be deposited in special landfills for toxic waste. These polygons are complex and require significant costs. In this regard, there is a need for such methods of purification of galvanic sewage sludge, which may be used in other industries or will have fourth class of hazard or below. This article compares the main methods of purification of galvanic waste waters in general and galvanic sludge in particular, currently introducing new techniques for treating industrial effluents. One of them considers treatment of galvanic waste water by means of suspensions of ferriferous hydrosol that is an electric generated coagulant derived from waste forming, steel wool, etc. There is a sort of experience already acquired in some countries how to use of ferropericlase.
\end{abstract}

\section{Introduction}

Galvanic sludge is currently considered as the most dangerous wastes, which are formed during purification of galvanic waste waters. The slimes of galvanic production are the most toxic industrial waste and sources of heavy metals to the environment. The accumulation of toxic waste leads to the pollution of the biosphere due to leaching of heavy metals from the sludge and introducing them to the soil, surface water and groundwater. Galvanic sludge has a negative impact on the human body: are powerful stimulants and activators of cancer and cardiovascular diseases $[1,2]$. Disposal of sewage sludge and other waste products is the main section of regional programs for disposal of industrial waste.

Galvanizing is an electrolytic deposition of a thin layer of metal on the surface of any metal object to protect it from corrosion, improve wear resistance, protection of cementation or for decorative purposes [3-6]. Galvanic coatings are used in many industries: machinery, metal industry, electrical equipment production. According to the Federal service of state statistics of Russia for 2014 there are more than 44 thousand metallurgical production and production of metal products, more than 42 thousand machinery and equipment enterprises, more than 35 thousand of enterprises manufacturing

*Corresponding author: nmakisha@gmail.com 
electrical and electronic, optical equipment, about 10 thousand of enterprises producing vehicles and equipment (as for 2013) [7-8].

\section{Methods of galvanic waste water treatment}

The methods most frequently used for treatment of galvanic wastewater are: chemical, ionic exchange, electro coagulation, electro dialysis, reverse osmosis $[3,9,10]$.

\subsection{Chemical methods of treatment}

Reagent treatment of sewage from ions of heavy metals is carried out by their transfer to poorly soluble compounds (hydroxides or basic carbonates) within the neutralization of wastewater using various alkaline reagents [11].

This method of purification of galvanic wastewater is relatively common due to several advantages: relative simplicity, reliability, ease of automatic $\mathrm{pH}$ control. However, amphoteric properties makes achievement of requirements impossible, since some metals it become almost impossible to define such $\mathrm{pH}$ range in which all the ions of heavy metals could precipitate simultaneously to limited values. In addition, the presence in solution of complexing agents complicates the task of extraction of metals $[2,12]$.

One of the main drawbacks of this method is the need to separate waste and bulky equipment, whereby the location of the wastewater treatment facilities requires large areas and a large volume of construction works. In addition, serious environmental problems arise due to the large consumption of reagents and production [13,14].

The features of the sludge after the chemical cleaning of galvanic wastewater should also be pointed out. The galvanic sludge formed after reagent sewage of waste treatment (when lime milk is a alkaline reagent), shows the domination of calcium, which concentration reaches $25-28 \%$ (as forCa $\left.(\mathrm{OH})_{2}\right)$. The content of $\mathrm{Fe}(\mathrm{OH})_{3}$ does not exceed $20 \%$. Other metals in this group of galvanic sludge are in amount not exceeding $10 \%$ of each species. If the purification of galvanic wastewater used waste etching solution containing $\mathrm{FeSO}_{4}$, the Iron content is more than $20 \%$. If salaciously agents are soda ash or sodium alkali, no single metal dominates, and their content as for hydroxide is not more than $10 \%$ each. Another group of galvanic sludge contains product of etching the surface of aluminum along with heavy metals and calcium foods, is also supplied to the station of neutralization. Their content does not exceed $10 \%$, and the dried product is more dispersed[3,15,16].

Lime reagents complicate the solution of the problems associated with the disposal of sludge, so the resulting sludge have to be placed in special landfills (expensive and has limited capacity) for toxic waste.

\section{2 lon exchange methods of treatment}

Ion exchange wastewater treatment is the process of interaction of the solution with the solid phase (the ion exchanger) that is able to exchange its ion to ions that are in solution. Ion exchange purification allows removing from the wastewater and disposing heavy metals (copper, Nickel, zinc, etc.), chromium, cyanide compounds, and radioactive substances. This ensures treatment of waste water to the requirements and makes possible of its reuse in technological processes.

This method is effective only at low concentrations of heavy metals in solutions, and requires prior separation of organic substances. In addition, ion exchange purification does not solve the problem of disposal of eluates. Another drawback of this method is the 
considerable investment and operating costs (high cost of reagent per unit of the remote metal) [16-18].

\subsection{Electric coagulation treatment}

The method of electro coagulation is the second spread method after the chemical in the CIS countries. The essence of electrochemical treatment of water is when DC voltage applied to the electrodes the process of dissolving of the iron anodes begins. Electric and chemical treatment has the following results:

1. Change of the dispersed state of impurities due to their coagulation under the influence of an electric field and the pinning bubbles of the electrolytic gas on the surface of the coagulating particles, which ensures their subsequent flotation.

2. Sorption of heavy metals on the surface of the electrolytic ally obtained metal oxides.

3. Chemical reduction of ions of $\mathrm{Cr}^{6+}$ ions to $\mathrm{Cr}^{3+}$.

But this method also has certain drawbacks:

- low reliability of operation of a sewage treatment plant due to the passive state of electrodes; clogging of space between electrodes and the oscillation of contaminant concentration in the effluent (in general this method suits only for industries with stable flow, requires equalization reservoirs and additional facilities for them);

- Hard treatment of volley discharges;

- Difficult sludge precipitation due to hydrogen evolution;

- High cost of electricity, potash and steel sheet;

- Unstable deposition of metals from chelating agents.

After treatment with electric coagulation of wastewater galvanic sludge normally contains more than $50 \%$ of iron in calculation of $\mathrm{Fe}(\mathrm{OH})_{3}$. The content of each of other heavy metals, as a rule, does not exceed $10 \%$ [19-21].

\subsection{Reverse osmosis treatment of galvanic wastewater}

Reverse osmosis and ultra filtration processes based on filtration of solutions through a semi permeable membrane under pressure exceeding the osmotic pressure. Membranes allow passing solvent molecules and stop the solute. This method of purification of galvanic wastewater helps to achieve the requirements of quality treatment. The return to $60 \%$ of treated water in the circulating cycle and the possibility of disposing of heavy metals are the undeniable advantages of reverse osmosis over other methods of purification of galvanic wastewater.

However, this method also has some serious shortcomings that leads to its small spread in wastewater treatment facilities of enterprises. The main drawbacks of this method are: the necessity of preliminary removal from oils, surfactants, solvents, organics, suspended solids from waste water; relatively high cost of membranes, the complexity of the operation, requirements for high integrity systems; the sensitivity of the membranes to changes in the parameters of cleared sewage.

Method of reverse osmosis is one of the most expensive methods of purification of galvanic waste waters. The introduction of electro dialysis and reverse osmosis is limited due to complexity of the equipment and expensive operation [22-24].

\section{Experimental research}

There were studies conducted in Lithuania that showed that efficiency of electro coagulation depends on colloidal suspension of iron compounds which is formed during 
electrolysis and allows to remove heavy metals from the water even if the reagent to obtain separately and dosed it in the treated waste water. The parameters of the working solution are much easier to adjust than the parameters of the production flow. The solution may have characteristics allowing obtaining a coagulant from of metal waste, instead of expensive steel [25].

The researches helped to develop a system of galvanic wastes treatment based on the use of electro generating coagulant derived from waste forming, steel wool, etc. Final product is called ferropericlase.

Ferriferous hydrosol is produced electrochemically in a special generator. The waste of the iron or iron shavings is put into special anodic cell and dissolved. Special supplement is introduced to intensify the process and stabilize the formed colloidal nanoparticles. The electrochemical reaction in the solution can be divided into the two stages:

1. Forming of $\mathrm{Fe}^{2+}$ on anode surface.

2. Hydrolysis and the formation of insoluble nanoparticles as result of interaction of the components of the solution.

The reaction sequence is as follows:

$$
\begin{gathered}
\mathrm{Fe}->\mathrm{Fe}^{2+}+2 \mathrm{e}-(1) \\
\mathrm{Fe}+\mathrm{OH}-<->\mathrm{FeOH}^{+}+2 \mathrm{e}-(2) \\
\mathrm{FeOH}_{\text {sol. }}^{+}+\mathrm{OH}^{-}<->\mathrm{Fe}(\mathrm{OH})_{2 \text { sol. }}(3) \\
\mathrm{Fe}(\mathrm{OH})_{2 \text { sol. }}<->\mathrm{Fe}(\mathrm{OH})_{2 \text { sol }}(4) \\
\mathrm{Fe}(\mathrm{OH})_{2 \text { sol. }}<->\mathrm{FeOH}{ }^{+}+\mathrm{OH}^{-}(5) \\
\mathrm{Fe}(\mathrm{OH})<->\mathrm{Fe}^{+}+\mathrm{OH}^{-}(6)
\end{gathered}
$$

The resulting suspension of ferriferous hydrosol has different mechanisms of action: it has the properties of a sorbent and coagulant, reducing agent and chemical reagent. The iron hydroxide reacts with ions, hydroxides and micelles of chromium, Nickel, copper, zinc, cadmium, lead and other metals. The depth of waste water treatment is enhanced by the formation of mixed crystals and chemical compounds and due to their very intensive adsorption [26,27].

Table 1.Pollutant concentration in sludge after different type of treatment.

\begin{tabular}{|c|c|c|}
\hline \multirow{2}{*}{ Metals } & \multicolumn{2}{|c|}{ Sludge production } \\
\cline { 2 - 3 } & Chemical neutralization, $\mathbf{m g} / \mathbf{l}$ & Use of ferropericlase, $\mathbf{~ m g / \mathbf { l }}$ \\
\hline $\mathrm{Zn}$ & $<252.0$ & $<0.01$ \\
\hline $\mathrm{Pb}$ & $<0.05$ & $<0.05$ \\
\hline $\mathrm{Ni}$ & 2.5 & $<0.05$ \\
\hline $\mathrm{Cr}$ & 5.37 & $<0.01$ \\
\hline
\end{tabular}

Table 2. Waste water treatment with ferriferous hydrosol for various industries.

\begin{tabular}{|c|c|c|c|}
\hline \multirow{2}{*}{ Waste water } & \multirow{2}{*}{ Metal } & \multicolumn{2}{|c|}{ Concentration, mg/l } \\
\cline { 2 - 4 } & & In & Out \\
\hline \multirow{2}{*}{ Galvanic industry } & $\mathrm{Zn}$ & 23.4 & 0.005 \\
\cline { 2 - 4 } & $\mathrm{Cr}$ & 96.0 & 0.01 \\
\cline { 2 - 4 } & $\mathrm{Cu}$ & 46.0 & 0.01 \\
\hline \multirow{2}{*}{$\begin{array}{c}\text { Printing plates } \\
\text { manufacturing }\end{array}$} & $\mathrm{Pb}$ & 1.56 & 0.05 \\
\cline { 2 - 4 } & $\mathrm{Ni}$ & 1.05 & 0.05 \\
\cline { 2 - 4 } & $\mathrm{Fe}$ & 113.0 & 0.01 \\
\hline
\end{tabular}

High efficiency of formation of hydrates of heavy metal ions is due to the simultaneous occurrence of exchange and redox reactions. The ferriferous hydrosol effectively removes heavy metals, surfactants, oil, coolant, organic additive, etc from wastewater. Purified water is suitable for reuse in the basic or auxiliary production. Tables 1 and 2 show the efficiency of treatment by means of ferriferous hydrosol in comparison with chemical reaction (Table 1) and for various industries (Table 2) [28,29]. 


\section{Galvanic sludge features}

Toxic sludge that appears through galvanic wastewater treatment process represents a significant threat to the environment and causes a serious problem for industrial companies. Such sludge cannot be exported to common landfills; meanwhile special landfills demand special construction and high costs. All these factors force to find methods to reduce volume of industrial waste and their level of toxicity. According to the modern requirements, the sludge should be:

- Lowtoxic;

- suitable for utilization in industries, which final product do not allow residues of toxic substances to turn into an active form;

- Maximumdewatered;

- Suitable for utilization in industries where the hydrophilic form of sludge does not lead to additional consumption of energy for evaporation of water.

Sludge, formed as a result of treatment using the suspension of ferriferous hydrosol meets these requirements.

The chemical composition of the sludge that appears after wastewater treatment using ferriferous hydrosol can be represented as a mixture of exaggerated iron with adsorbed metal compounds. According to $\mathrm{x}$-ray phase analysis, the sludge generated during wastewater treatment with ferriferous hydrosol, do not contain well crystallized phases.

Electronic microscopic studies have shown that the dried sludge is a highly dispersed material with a strong tendency to agglomeration. The particles of the sludge have an irregular, close to spherical shape. The size of most of them is 0.2-0.8 microns.

Based on the chemical composition of the sludge containing compounds of polyvalent metals, it is obvious that they can be used as raw material for obtaining a number of target products, in particular iron pigments, modified with chromium, zinc, nickel, copper, fluxing additives for the production of ceramic and construction materials [22, 30-32].

\section{Conclusions}

The main advantages of the method of sewage treatment using ferropericlase:

- Higher quality of wastewater treatment than the traditional reagents.

- Non-toxic effluent.

- No extra salinity of effluent.

- No split of flows on the nature of the contamination.

- Zero chemical aggressiveness of ferropericlase.

- Better conditions for personnel.

- Low toxicity of wastewater sludge that can be exported to ordinary landfills or used as feedstock for the production of building materials, pigments and glazes.

\section{References}

1. N. Makisha, V. Scherbakov, A. Smirnov, E. Scherbina, IJAER10, 44347-44349 (2015)

2. V. Scherbakov, E. Gogina, T. Schukina, N. Kuznetsova, N. Makisha, E. Poupyrev, IJAER10, 44353-44356 (2015)

3. E. Gogina, I. Gulshin, Pr. Eng.117, 107-113 (2015)

4. A.G. Pervov, A.P. Andrianov, T.P. Gorbunova, A.S. Bagdasaryan, Petr. Chem.55 (10), 879-886 (2015)

5. I. Gulshin, A. Kuzina, IJAER10, 42618-42623 (2015) 
6. E.S. Gogina, O.V. Yantsen, O.A. Ruzhitskaya, AMM 580-583, 2354-2357 (2014)

7. O.A. Ruzhitskaya, E.S. Gogina, AMR919-921, 2141-2144 (2014)

8. A. Volkov, V. Chulkov, R. Kazaryan, M. Fachratov, O. Kyzina, R. Gazaryan, AMM580-583, 2281-2284, (2014)

9. N. Makisha, E. Gogina, AMM361-363, 632-635 (2013)

10. A.G. Pervov, A.P. Andrianov, E.B. Yurchevskiy, Petr. Chem.55 (10), $871-878$ (2015)

11. O.A. Ruzhitskaya, E.S. Gogina, AMR919-921, 2153-2156 (2014)

12. E. Gogina, N. Makisha, AMM587-589, 636-639 (2014)

13. E. Gogina, A. Pelipenko, MATECCONF73, 03007 (2016)

14. V.N. Varapaev, S.A. Doroshenko, A.Y. Trotsko, A.V.Doroshenko, IJAER10, 4258842592 (2015)

15. N. Makisha, O. Yantsen, AMM587-589,640-643 (2014)

16. O. Kuzina, E. Pankratov, V. Tkachev, MATECCONF 86, 05023 (2016)

17. N. Makisha, E. Gogina, AMM 587-589, 644-647 (2014)

18. V. Orlov, A. Andrianov, AMM580-583, 2398-2402 (2014)

19. N. Makisha, Y. Voronov, E. Poupyrev, V. Volshanik, IJAER10, 41919-41922 (2015)

20. V.N. Varapaev, A.V. Doroshenko, I.Y. Lantsova, Pr. Eng.153, 816-823 (2016)

21. N. Zaletova, Y. Voronov, N. Makisha, IJAER10, 42454-42455 (2015)

22. N. Makisha, E. Gogina, AMM361-363, 628-631 (2013)

23. E.S. Gogina, O.A. Ruzhitskaya, O.V. Yantsen. AMR919-921, 2145-2148 (2014)

24. N. Makisha, E3sconf6, 01002 (2016)

25. A.G. Pervov, A.P. Andrianov, DWT35 (1-3), 2-9 (2011)

26. E. Gogina, I. Gulshin, AMM580-583, 2367-2369 (2014)

27. A. Volkov, O. Kuzina, Pr. Eng.153, 838-843 (2016)

28. N. Makisha, Pr. Eng.165, 1087-1091 (2016)

29. A.A. Volkov, A.V. Sedov, P.D. Chelyshkov, D.A. Lysenko, A.V. Doroshenko, IJAER10, 43269-43272 (2015)

30. N. Makisha, Pr. Eng.165, 1092-1097 (2016)

31. E. Gogina, I. Gulshin, Pr. Eng.153, 189-194 (2016)

32. A.G. Pervov, A.P. Andrianov, V.A. Chukhin, R.V. Efremov, IJAER10, 43517-43525 (2015) 